\title{
A New Perspective to Study Children's Literature: from the Systemic-functional Grammar Perspective
}

\author{
Yanhua Cao ${ }^{1, *}$, Jianjun Yin ${ }^{2}$ \\ ${ }^{1}$ School of Foreign Languages, Nantong University, China \\ ${ }^{2}$ College of Education and Human Development, Jackson State University, USA
}

Copyright $\mathrm{O} 2016$ by authors, all rights reserved. Authors agree that this article remains permanently open access under the terms of the Creative Commons Attribution License 4.0 International License

\begin{abstract}
The importance of children's literature has never been over emphasized. This research aimed to explore a new perspective to study children's literature. Document study demonstrated that previous studies on children's literature were mostly from the perspectives of genre and content as well as the interaction between readers and the text. The linguistic studies on interpersonal meaning give light on the study on children's literature. The document study in this paper illustrated the possibility to apply the systemic-functional grammar to the research on children's literature. This research provides a more profound perspective to look into the linguistic resource in children's literature, which have great influence on their development.
\end{abstract}

Keywords Children's Literature, Interpersonal Meaning, Systemic-functional Grammar

\section{Introduction}

Reading plays the most important role in children's development. Jacobs and Tunnell claimed, "Reading is one of life's activities that simultaneously yields both pleasure and benefit" [1]. "... for the child was made through texts and tales he or she studied, heard, and told back," argued Lerer [2]. According to the data in the 2013-14 dataset from Measure of America, however, in 2010, in the United States (US), the school enrollment rate was $77.6 \%$, while the graduation degree rate was only $28.2 \%$, whereas $10.4 \%$ of the population of people received education less than high school, and $21.8 \%$ of high school freshmen failed to graduate after 4 years [3]. This situation calls for improvement from the educational perspective.

In order to raise achievement and close achievement gaps, the United States government issued the Elementary and Secondary Education Act of 1965 (ESEA) and the No Child Left Behind Act (NCLB) in 2001. President Barack Obama continued education reform on the Act to foster the development of American education. In 2009, he created a
\$4.35 billion United States Department of Education contest, Race to the Top, to inspire states to participate in educational reform. Many states, therefore, changed their policies to align with the Common Core Standards for K-12. President Obama's administration "invests and strengthens early childhood education, care, and development for nation's young learners ... to prevent achievement gaps before they start, and invests from an early age in children as our most critical national resource" [4]. In the end of 2015, Obama went a step further, and signed the Every Student Succeeds Act.

As an important part of the education reform, raising the bar for early learning is one of the most important requirements, with an emphasis on the following: (1) rigorous standards and assessments that help prepare students for college and career, (2) smarter data systems that help track student progress and improve instruction, (3) ambitious support to recruit, prepare, and advance effective teachers and principals, and (4) focused attention and resources to dramatically improve lowest performing schools. Under the Race to the Top reform, Head Start is being reformed and expanded to "provide comprehensive child development services that foster children's growth in social, emotional, cognitive and physical development" [4].

All these reforms are based on the premise that higher scores can lead to higher education quality and that reading is the foundation for the development of all other academic skills. It is generally accepted that early mastery of reading is a good predictor of future academic success. Mississippi, for example, sets guidelines and standards for 3 year and 4 year-olds in early childhood education, with language art and literacy development being the first important items [5]. It becomes one of the important focuses of the guidelines and standards to enlarge children's vocabulary, enhance children's reading comprehension ability, and promote their writing skills development. Although the guidelines mention the goal of fostering children's development in understanding and communicating their feelings through language learning, this goal still does not attract enough attention. Fish (2011) and Freedman (2003) emphasized 
emotional literacy and defined it as the ability to know words and concepts to negotiate emotions [6,7]. However, studies on the interpersonal meaning of the language in children's books are still rare.

In order to encourage children to develop their language and reading skills, educators, researchers, major book publishers, and retailers recommend various children's literature from different perspectives. However, most of the book lists are designed according to the vocabulary level, the sentence structure, the story theme and content, the genre, the lessons in the book, etc.[1, 8,9,10]. Furthermore, criticisms of children's books are mostly from the perspective of theme, role characteristics, and morality. The research on children's literature from the linguistic perspective of interpersonal meaning has not been fully conducted.

\subsection{Problem Statement}

According to the federal government's Race to the Top reform and state governments' educational standards and guidelines [4,5], federal and state governments have put high stakes on children's development in language arts and literacy. As we all know, however, children develop holistically. They develop physically, cognitively, socially, and emotionally. In addition to fostering children's literacy development through vocabulary and sentence learning and promoting emotional and social development by values teaching through story content, children's literature could also enhance children's emotional social development through the influence of text itself.

According to Halliday, language has its interpersonal function, through which a discourse exerts its influence on a reader's emotion and behavior [11]. However, there is little research on the interpersonal meaning of children's literature or on how writers exert their influence on children through discourses. Therefore, there is a need to consider: how words were utilized to impact children's social and emotional development?

\subsection{Purpose of the Study}

The purpose of this study is to review previous studies on children's literature and explore a new perspective to look at children's literature. Halliday's systemic-functional grammar provides a primary theoretical tool to explore the interpersonal meaning of a discourse, and Martin's appraisal theory extended the exploration into the interpersonal meaning. In addition, the intertextuality theory offers a new perspective on interpersonal meaning from the discourse level. However, these three theories only deal with part of the language resources that are realizing interpersonal meanings. Is there the possibility to combine the three theories to conduct a comprehensive study on the interpersonal meaning of the text of children's literature? This is a significant study because it explores a new linguistic perspective of interpersonal meaning to look at children's literature.

\subsection{Research Questions}

The research questions that guided this study were employed to solve the research problem: how writers employ words to impact children's social and emotional development?

1. What are the previous studies on children's literature?

2. What are the linguistic methods that can be employed?

3. How can the linguistic tools be employed to explore the influence of children's literature text on children's social and emotional development?

\subsection{Basic Theories on Interpersonal Meaning}

Thompson points out that "in [a] functional approach to grammar we essentially equate meaning with function" [12]. Therefore, the interpersonal meaning is equivalent to the interpersonal function of language. Halliday defined three meta-functions of language in his systemic-functional grammar, in which he proposed the concept of interpersonal function of language. According to Halliday, the interpersonal meta-function realizes the interaction between speakers or writers and their addressees, the grammatical resources for enacting social roles in general, and speech roles in particular [12]. That is to say, the interpersonal function of language could establish change and maintain interpersonal relationships through language. In systemic-functional grammar, the interpersonal function of language is primarily realized through mood and modality.

The systemic-functional grammar theory is the most fundamental theory in investigating the interpersonal meaning. Halliday maintains that mood, modality and key are the basic semantic systems to realize the interpersonal function of language [12]. Li proposes to extend modality in systemic-functional grammar to the discourse level in his study on modality [13]. In 2001, Li explored the multiple means to realize interpersonal meaning: the interpersonal meaning at the level of discourse, the interpersonal meaning in the resources realizing ideational, and textual meaning [14]. Li endeavored to reframe a three-element, two-level model of interpersonal meaning from the epistemic, evaluative, and interactional aspects, providing a comprehensive and profound interpretation of interpersonal meaning [15].

Based on Halliday's theory, Martin extended the investigation on interpersonal meaning. Martin's approach to exploring interpersonal function, called the appraisal system, tends to go beyond a detailed focus on the semantics of evaluation and establishes a new lexicon-grammatical framework in systemic-functional linguistics. The appraisal system, according to Martin consists of three interacting domains: attitude, engagement, and graduation. Attitude tackles feelings; engagement is concerned with the way in which values are sourced and readers aligned; graduation deals with the grading of meanings by adjusting the force of 
a value or the focus of a categorical boundary [16].

At the discourse level, the study of intertextuality contributed a new perspective to the study of interpersonal meaning of discourse. Xin (2005) delved into the intertextuality of discourses and stated his insightful viewpoints on it; in which he pointed out the applicability of intertextuality to future studies on interpersonal meaning. In this research, intertextuality was applied to probe into the interpersonal meaning in children's literature [17].

The studies of intertextuality were formerly confined in the field of literacy criticism. In this research, we focused on genre intertextuality, one of the most important topics in intertextuality.

Genre intertextuality refers to the phenomenon of blending different styles, register or genre features into one discourse. Halliday and Hasan argued that different genres set different subject positions or participant's types, which have different structural features [18]. These are called generic structure potential, which could assign specific roles for participants of the discourse. Xin (2005) points out that "every genre has its own meaning potential, standing for the interest of a different social group or class," and that "when writing or reading a discourse, the writer or the reader has to depend on the meaning potential, consciously or unconsciously, to make choices" [17]. Hence, different genres achieve various expected communicative effects through setting, different subject positions, and corresponding reading positions. Reading position enables readers to understand the discourse, but simultaneously, readers are assigned certain roles in the discourse. That is to say, the discourse employs genre to inform readers who they are, how, and when they can participate in certain social activities. When a discourse constructs a reading position, it also assigns and consolidates the subject position. Therefore, genre intertextuality indicates that the speaker may manipulate the use of genre in the discourse to achieve his communicative goal.

\subsection{Research Methodology}

This research aimed to explore a new perspective to look at the children's literature. Therefore, the research, with document analysis, reviewed previous research on children's literature and the research that used the proposed linguistic theories, and then explored the new linguistic perspective to deal with children's literature.

Since we study children's literature, we first need to define children's literature. According to Payne and Barbara, children's literature refers to "books written for children readers and listeners with the intent to provide one or more of the following: moral or social instruction, amusement, imagination and curiosity, compassion and empathy, an understanding of the child's place in the world" [19]. The definition of children's literature reveal that the function of children's literature is far more than entertainment. Children's literature have great influence on children.

In this research, I explored how words in children's literature influence children's social and emotional development. I select systemic functional grammar as a possible analysis theory because this theory looks into the function of language. Systemic functional Grammar is "a full-blown theory of language, developed by the British linguist Michael Alexander Kirkwood Halliday" [20]. The core of this theory is Halliday's understanding of language that language has three meta-functions: ideational function, interpersonal function and textual function. According to Halliday and Matthiessen, interpersonal function, also called interpersonal meaning, is language as action. Language is always enacting people's personal and social relationships with other people around them, informing or questioning, giving an order or making an offer, and expressing their appraisal of and attitude towards whomever and whatever they are addressing [11]. Therefore, it is possible to employ systemic functional grammar to explore the influence of children's literature on children.

\section{Studies on Children's Literature from Different Perspectives}

Children's literature attracts lots of researchers' interests, and a great number of researchers conducted their research from various perspectives like genre, content, theme, values, teaching, history, background, and social influence. Generally, studies on children's literature can be categorized into two groups on the basis of research perspectives: the perspective of genre and content and the perspective of interaction between readers and text.

\subsection{Study Children's Literature from the Perspectives of Genre and Content}

First, genre and content of children's literature are popular topics for researchers in children's literature fields. Asutay studied children's tales from the genre perspective and analyzed tales, type, properties of narration in tales, the significant function of tales in the culture of origin, and its relation with children. The author emphasized the educational function of tales in teaching children values of certain cultures and in influencing children's imaginative and mental abilities [21]. Jacobs and Tunnell studied the content and teaching of children's literature. They provided a practical overview of children's books and its use with young readers for university student teachers [1].

Fredericks emphasized the positive influence of children's literature on children's social development, and proposed a literature-based approach to social studies instruction. Fredricks analyzed the content and theme of children's literature, and arranged them in different groups as means for scaffolding children's social development [22]. Green, Scott, and Oldendorf looked into the influence of various religions on children's literature. Green et al. acknowledged the influence of children's literature, and tried to help children understand other religions through children's literature so 
that they could avoid possibly the misunderstanding of other religions [23].

Bickford and Rich examined children's literature, identified, and balanced misrepresentations. They also modeled how to include such literature in the classroom, using age appropriateness as a construct [24]. Todres and Higinbotham examined what children could learn about their own rights, the rights of others, and the role of children's rights, in a democratic society. They pointed out that children can experience profound questions about rights through children's literature [25].

McCulloch studied the evolution of children's literature in the context of culture and social development, as well as the criticism on children's literature [26]. Gopalakrishnan and Persiani-Becker explored multicultural children's literature with a critical approach. They explored critical issues (such as censorship, gender, equity, and violence) and social focuses (such as war, terrorism, prejudice, bullying, disabilities and social and technology development) in multicultural children's literature [27]. Truglio examined the heroism and melancholia in Italian children's literature [28].

Pearson studied the commercial, creative, and critical characteristics of "the second golden age" of children's literature in Britain [29]. Serafni and Layne discussed children's literature from both author-illustrator's and literacy professor's perspectives, and suggested a look at children's literature both from its inherent lessons and its words, image, and even layout [30].

\subsection{Study children's literature from the perspective of the interaction between readers and text}

As shown in previous mentioned literature, children's literature were frequently used as a method to educate children with certain social values. Then, the interaction between readers and children's literature becomes another research focus in this field. Galda started from the Transactional Theory and claimed that reader infuses meaning and that text guides and constrains [31]. Shikhmanter found the possibility of children's literature to help with trauma on personal and cultural level [32]. Lerer studied the development of children's literature from the perspective of the reader's experience of literature. He said that children's literature with different genres addresses the changing environment children live in and helps children find the world within the book and books in the world [2]. Walsh explored Kipling's Children's Literature from the post-colonial perspective, and claimed that children's literature could not describe the child [33]. Nel found racial imagination in Dr. Seuss's books [34]. Horne studied the history of early British children's literature, and he considered the history of children's literature as a means to train children in private and public virtue [35]. Reynolds studied the impact of World War I history on children's literature and maintained that children's literature at that period reflected the social situation and influenced children's behavior [36]. Loh-Hagan found good trends in
Asian-American children's literature, which reveals the fact that children's literature reflects the change of the society children are living in, and it will have an influence on children's social development [37]. Miller investigated the scandals concerning children's literature, and concluded that the debate was "a battle of worldviews that recognizes the transformative ability of literature and the symbolic potential of the child reader" [38]. However, most of those researches explored readers' perceptions on children's literature, and there was few research on the linguistic features of children's literature.

\subsection{Summary}

Just as analyzed above, Paul and Nel listed 49 most popular keywords for children's literature in their book, but almost all of them are in the category of genre, education, psychology, culture, and literacy criticism [39]. None of the listed key words belongs to the linguistic area. These studies explored the influence of children's literature through examining theme, content, major characters, or investigating the interaction between children and their literature. However, there is little research on how discourse itself influences children as readers.

\section{Studies on Interpersonal Meaning}

This research aims to study how the text of children literature influence children. Therefore, we study language as a tool to manipulate people's perception and behavior. This falls in the area of interpersonal meaning of language. Therefore, the theory on the interpersonal meaning can be the theory to guide our study on children's literature and solve our research question.

\subsection{The Definition of Interpersonal Meaning}

Halliday claimed that all languages are composed of three kinds of meaning, the ideational, interpersonal, and textual meaning. Interpersonal meaning refers to the meta-function of language to act on the others [11]. Thompson insisted that "in functional approach to grammar we essentially equate meaning with function" [12]. Thus, the terms can be used interchangeably. In this research, therefore, we equated the interpersonal function of language with the interpersonal meaning of language.

Halliday maintained that one of the main purposes of communication is to interact with other people; to establish and maintain appropriate social links with them [11]. Thompson also asserted that language is used to interact with other people, to establish and maintain certain relationships with them, to influence their behavior, to express one's own viewpoint, and to elicit or change others [12]. Furthermore, Halliday pointed out that "while construing, language is always enacting; enacting our personal and social relationships with the other people around us" [11]. That is to 
say, interpersonal meaning of language realizes and manipulates the relationship between speakers/writers and hearers/readers of different roles.

\section{Thompson argues:}

We tell other people things for a purpose: we may want to influence their attitudes or behavior, or to provide information that we know they do not have, or to explain our own attitudes or behavior, or to get them to provide us with information, and so on [12].

Just as $\mathrm{Hu}$ and $\mathrm{Zhu}$ (1989) concluded, the interpersonal function of language is the speakers' "meaning potential" [40]. With this function, speakers can engage in a certain situational context to express their attitudes and references, and try to influence other's attitudes and activities as well. In other words, interpersonal meaning of language aims to achieve a specific purpose in a certain situational context.

Hence, interpersonal meaning is a language resource, which enables speakers/writers to establish relationships among the participants of their discourses, so as to attain specific goals in certain contexts. In this research, we examined how the interpersonal meaning is realized in children's literature. In another words, we explored how the text of children's literature exert its influence on children readers.

\subsection{Previous Studies on Interpersonal Meaning}

According to McCarthy and Carter, the meaning of language usually consists of two different tiers: one is the semantic meaning that is independent from context; the other is contextual meaning that occurs in a particular context [41]. Therefore, the same utterance will be employed to express different meanings due to the difference of context. General linguistics' focus switches from the ideational, content-based and stable relationship between forms and meanings to the interpersonal, variable and negotiable aspects of language [13]. A wealth of studies has been conducted on interpersonal meaning in a diversity of discourses from various perspectives.

\subsubsection{Studies from Social Linguistic and Pragmatic Perspectives}

Social linguists pay special attention to interpersonal meaning of language. Lakoff found that the reason women tend to use more "fancy" colorful words and often add tag questions to statements is that they are less sure about themselves than men [42]. Fasold claimed that

When people use language, they do more than just try to get another person to understand the speaker's thoughts and feelings. At the same time, both people are using language in subtle ways to define their relationship to each other, to identify themselves as part of a social group, and to establish the kind of speech event they are in. [43]
Brown and Gilman (as cited in Fasold, 1990, p. 3) investigated the usage of the second personal pronouns in French, German, Italian, and Spanish and discovered that the use of pronoun is administrated by power and solidarity [43]. Their research concentrated on the phenomenon, that the participants are assigned social roles through interpersonal meaning in discourses.

Pragmatics scholars put their research emphasis on the process and how interpersonal meaning is realized in the context of certain discourse. Grice (1975) developed the cooperation principle, which includes four "Maxims," to help people to achieve effective communication through cooperating with each other [44]. Leech proposed the concept of politeness, and suggested principles to maintain good interpersonal relationships between speakers and the audience [45].

Brown and Levinson put forward their "Politeness Theory" [46]. In their theory, they identified positive face and negative face. Positive face is the desire to be approved of by others; negative face is the desire to be unimpeded by others. According to their theory, people always take advantage of various strategies to minimize the degree of face threatening, so as to keep expected relationships with others and save face.

\subsubsection{Studies from the Systemic-Functional Linguistic Perspective}

Interpersonal meaning is primarily investigated under the framework of systemic-functional grammar. Halliday in his systemic-functional grammar model claims that mood, modality and key, are the basic semantic systems to realize the interpersonal function of language [11].

Li in her study on modality, proposed to extend Halliday's concept of modality to the discourse level [13]. Furthermore, $\mathrm{Li}$ attempted to construct a new framework of interpersonal meaning on the basis of functional grammar [14]. $\mathrm{Li}$ explored the interpersonal meaning at the discourse level, and the interpersonal meaning realized in the ideational and textual resources. Then she proposed to build a three-element two-level model of interpersonal meaning from the epistemic, evaluative, and interactional perspectives [14]. Following a series of research on interpersonal meaning, $\mathrm{Li}$ offered a more profound interpretation of interpersonal meaning [15].

Based on Halliday's theory, Martin created another approach to explore interpersonal function [16]. This approach, called the appraisal system, goes beyond a detailed focus on the semantics of evaluation and establishes a new lexicon-grammatical framework under systemic-functional linguistics. The appraisal system is composed of three interacting domains: attitude, engagement and graduation. Attitude deals with feelings; engagement attends to the ways in which values are sourced and readers aligned; and graduation is concerned with the grading of meanings, by adjusting the force of a value or the focus of a categorical boundary. 
In the light of Martin's appraisal system, Chen analyzed the interpersonal meaning of English automobile commercials from the perspective of appraisal resources, and found that automobile commercials employed the appraisal system to magnify the appealing features of the vehicles to attract audiences [47]. Qian, Zhang (2007), and Xue (2011) studied the application of appraisal systems in translation, and they agreed with the opinion that the appraisal system offers essential information for translators to interpret target language, as precise as possible $[48,49,50]$.

Eley and Adendorff employed the appraisal system to analyze Clem Sunter's transformational leadership [51]. They found that judgment choices and affect choices in Clem Sunter's discourses are consistent with his leadership paradigm and that the social context of that period maximized the effect of the Sunter's discourses.

The study of intertextuality also composes an important part in the study of interpersonal meaning of discourse. Xin, in his book, investigates intertextuality and states his insightful view of some implications on the study of interpersonal meaning from an intertextuality perspective [17]. Xin further explored the intertextuality analysis in discourse linguistics [52]. Zacharias and Evans analyzed early Christian literature from the intertextuality perspective [53]. Alzahrani explored the development of intertextuality theory [54].

\subsection{Summary}

The documents analysis above indicates that systematic functional grammar provides a comprehensive and sophisticated method to study interpersonal meaning of language. Therefore, such a theory can work as a valid tool to be employed to analyze the interpersonal meaning in children's literature. This linguistic theory can help us find out how the text of children's literature influence children.

\section{Conclusions}

The document analysis shows that most of research on children's literature focused on the content, or theme, and even the research looking into the interaction between readers and text mostly explored the values-education function of children's books. There is little research exploring the influence of the text of children's literature on children.

There are also few studies on children's literature from the angle of interpersonal meaning. Guijarro analyzed the interpersonal meanings realized through verbal and visual modes in The Tale of Peter Rabbit [55]. The author applied Halliday's interpersonal meta-function framework and van Leeuwen's visual social semiotics to analyze the verbiage and illustrations, but he failed to probe into a deeper understanding of the interpersonal meaning of children's literature.

Therefore, it is possible to conduct studies on children's literature from the perspective of interpersonal meaning, and the interpersonal meaning analysis will promote the study on children's literature. Such research will help people understand how the writers or speakers exert their influence on audience through discourses.

\section{Limitations}

The research is conducted through document analysis, which contains the author's subjective understanding of the work, and might affect the objectiveness of the research. Other resources, criticism of the book and readers' reviews, can be included to reduce the effect of researcher's subjectiveness in further study. Moreover, quantitative research can also be taken in the future on children's literature corpus for a more objective understanding of the interpersonal meaning in children's literature.

\section{REFERENCES}

[1] Jacobs, J. S., \& Tunnell, M. O. (2004). Children's literature briefly. Columbus: Pearson, Merrill Prentice Hall.

[2] Lerer, S. (2008). Children's literature: A reader's history, from Aesop to Harry Potter. Chicago, IL: University of Chicago Press.

[3] Measure of America. (2014). Retrieved from http://www.mea sureofamerica.org/data-table-download/

[4] White House. (2014). Retrieved http://www.whitehouse.gov/ issues/education /early-childhood

[5] Mississippi Department of Education. (2013). Retrieved from http://www.mde.k12.ms.us/curriculum-and-instruction/earlychildhood.

[6] Fish, B. (2011). Raising emotionally intelligent children: Introduction to emotional intelligence. Ridgeland, MS: AMF Books.

[7] Freedman, J. (2003). Key lessons from 35 years of social-emotional education: How self-science builds self-awareness, positive relationships, and healthy decision-making. Perspectives in Education, 21(4), 69-80.

[8] ALSC. (2014). 2014 Notable children's books. Retrieved from http://www.ala org/alsc/awardsgrants/notalists/ncb

[9] Cavanaugh, M., \& Jones, B. (1999). The Barnes \& Noble guide to children's books. New York, NY: Barnes \& Noble.

[10] Hunt, G. (2002). Honey for a child's heart: The imaginative use of books in family life (3rd ed.). Grand Rapids, MI: ZONDERVAN.

[11] Halliday, M. A. K., \& Matthiessen, M. I. M. (2004). An introduction to functional grammar (3rd ed.). New York, NY: Hodder Arnold.

[12] Thompson, G. (2000). Introducing functional grammar. London, England: Edward Arnold. Beijing: Foreign 
Language Teaching and Research Press,2000

[13] Li, Z. (2000). Mood: From clause to discourse. Foreign Language Research, 4, 7-1.

[14] Li, Z. (2001). An extension of interpersonal meaning in systemic-functional grammar. Foreign Language Research, 1, 48-54.

[15] Li, Z. (2002). Interpersonal meaning in discourse. Shanghai: Shanghai Foreign Language Education Press.

[16] Martin, J.R. (2000). Close reading: Functional linguistics as a tool for critical discourse analysis. In L. Unsworth (Ed.), Researching language in schools and communities: Functional linguistic perspectives (pp.275-304). London, England: Cassell.

[17] Xin, B. (2005). Critical linguistics: Theory and application. Shanghai: Shanghai Foreign Language Education Press.

[18] Halliday, M. A. K., \& Hasan, R. (1989). Language, context, and text: Aspects of language in a social-semiotic perspective. Oxford, England: Oxford University.

[19] Payne, M., \& Barbera, J. R. (Eds.). (2010). A dictionary of cultural and critical theory (2nd ed.). John Wiley \& Sons.

[20] Malmkier, K. (Eds.). (2002). The linguistics encyclopedia (2nd ed.). London, England: Routledge.

[21] Asutay, H. (2013). The fantastic world of child literature: Tales. Electronic Turkish Studies, 8(13), 265-278.

[22] Fredericks, A. D. (2007). Much more social studies through children's literature: A collaborative approach. Westport, CT: Teacher Ideas Press.

[23] Green, C. R., Scott, E., \& Oldendorf, S. (2011). Religious diversity and children's literature: Strategies and resources. Charlotte, NC: Information Age Publishing.

[24] Bickford III, J. H., \& Rich, C. W. (2014). Examining the representation of slavery within children's literature. Social Studies Research \& Practice, 9(1), 66-94.

[25] Todres, J., \& Higinbotham, S. (2013). A person's a person: Children's rights in children's literature. Columbia Human Rights Law Review, 45(1), 1-56.

[26] McCulloch, F. (2011). Children's literature in context. London, England: Continuum.

[27] Gopalakrishnan, A., \& Persiani-Becker, K. (2011). Multicultural children's literature: A critical issues approach. Thousand Oaks, CA: Sage Publications.

[28] Truglio, M. (2015). Garibaldi's Shadows: Heroism and Melancholia in Italian Children's Literature. Children's Literature, 43(1), 51-83.

[29] Pearson, L. (2013). The making of modern children's literature in Britain: Publishing and criticism in the 1960s and 1970s. Farnham, Surrey: Ashgate.

[30] Serafni, F., \& Layne, S. (2013). Looking at children's literature from two perspectives. Reading Teacher, 66(7), 554-557.

[31] Galda, L. (2013). Learning from children reading books: Transactional theory and the teaching of literature. Journal of Children's Literature, 39(2), 5-13.
[32] Shikhmanter, R. (2014). Limitations as Possibilities: Uri Orlev's Holocaust Narratives for Children and Young Adults. Children's Literature, 42(1), 1-19.

[33] Walsh, S. (2010). Kipling's children's literature: Language, identity, and constructions of childhood. Burlington, VT: Ashgate.

[34] Nel, P. (2014). Was the Cat in the Hat Black?: Exploring Dr. Seuss's Racial Imagination. Children's Literature, 42(1), 71-98.

[35] Horne, J.C. (2011). History and the construction of the child in early British children's literature. Farnham, England: Ashgate.

[36] Reynolds, K. (2013). A prostitution alike of matter and spirit: Anti-War discourses in children's literature and childhood culture before and during World War I. Children's Literature in Education, 44(2), 120-139.

[37] Loh-Hagan, V. (2014). A good year for Asian-American children's literature. California Reader, 47(3), 40-45.

[38] Miller, A. (2014). Unsuited to age group: The scandals of children's literature. College Literature, 41 (2), 120-140.

[39] Paul, L., \& Nel, P. (2011). Keywords for children's literature. New York, NY: New York University Press.

[40] Hu, Z. \& Zhu, Y. (1989). An introduction to systemic-functional grammar. Changsha: Hunan Education Press.

[41] McCarthy, M., \& Carter, R. (1994). Language as discourse. Perspectives for language.

[42] Lakoff, R. (1973). Language and woman's place. Language in Society, 2(1), p. 45-80.

[43] Fasold, R. W. (1990). The sociolinguistics of language. Oxford, England: Blackwell.

[44] Grice, H. P. (1975). Logic and conversation. In A.P. Martinich (Ed.), Philosophy of Language (pp. 165-175). New York, NY: Oxford University Press.

[45] Leech, G. N., \& Leech, G. (1983). Principles of pragmatics (Vol. 285). London, England: Longman.

[46] Brown, P., \& Levinson, S. (1987). Politeness. Cambridge, England: Cambridge University Press.

[47] Chen, X. (2010). The interpersonal meaning of appraisal resources in English auto commercials. Journal of Changsha Railway Institution, 11(4), 179-180.

[48] Qian, H. (2007). Investigating unfaithful translations via the appraisal theory: A case study on perfume advertisements translation. Journal of Foreign Language, 6, 57-63.

[49] Zhang, X. (2007). The implication of appraisal theory on translation. Foreign Language Education, 28(6), 33-36.

[50] Xue, J. (2011). Appraisal theory in business translation. Journal of PLA University of Foreign Language, 34 (6), 88-109.

[51] Eley, G., \& Adendorff, R. (2011). The influence of the post-apartheid context on appraisal choices in Clem Sunter's transformational leadership discourse. Text \& Talk, 31(1), 21-52. 
[52] Xin, B. (2008). Intertextuality analysis in discourse linguistics. Foreign Language and Their Teaching, 1, 6-10.

[53] Zacharias, H., \& Evans, C. A. (2009). Early Christian literature and intertextuality. London, England: T \& T Clark.

[54] Alzahrani, M. (2011). From the death of the author to the death of intertextuality: The birth of cultural intertextuality. International Journal of the Humanities, 9(10), 189-197.

[55] Guijarro, A. J. M. (2010). A multimodal analysis of the tale of Peter Rabbit within the interpersonal meta-function. Atlantis, 32, 123-140. 